\title{
Democratic Hypocrisy and Out-group Threat: Explaining Citizen Support for Democratic Erosion
}

\author{
Gabor Simonovits* \\ $\mathrm{CEU}$
}

\author{
Jennifer McCoy ${ }^{\dagger}$ \\ GSU
}

July 28, 2021

\author{
Levente Littvay $\ddagger$ \\ $\mathrm{CEU}$
}

\begin{abstract}
With widespread democratic backsliding globally, people's support for democracyeroding leaders is receiving overdue attention. But existing studies have a difficulty disentangling contextual effects (such as who is in power at the time of the survey) from individual differences (like which party one supports and how strongly). Moreover, we lack evidence on the causal antecedents of these attitudes. We propose a novel survey experimental design to strip away the political context through hypothetical scenarios, allowing allow us to identify citizens' differential support for democratic norms when their own party is in vs out of power. Our findings indicate a large degree of democratic hypocrisy among the American public: individual support for norm-eroding policies increases when their citizens' own party is in power, an effect further amplified by strong expressive partisanship and threat perceived from the opposing party.
\end{abstract}

*Assistant Professor, Department of Political Science, Central European University. Email: simonovits@ceu.edu

'Professor, Department of Political Science, Georgia State University

${ }^{\ddagger}$ Professor, Department of Political Science, Central European University 
Anxiety about democratic backsliding is widespread globally as elected governments use democratic majorities or constitutional authority to enhance their own power. They then frequently undermine basic tenets of democracy in their quest to remain in power or to achieve fundamental political or social change. The 21st century threat to democracy is thus a form of gradual democratic erosion from within, carried out by elected leaders concentrating power with the support of voters (Bermeo, 2016; Diamond, Plattner, and Rice, 2015). Puzzlingly, in many countries such erosion has taken place even in the face of generally high support for democracy. Thus, the debate that this research note seeks to contribute to centers on the question of why citizens generally supportive of democracy tolerate or even encourage leaders to implement policies that erode existing democratic norms, rather than serve as a check on undemocratic political behavior by voting against such leaders (Graham and Svolik, 2020).

We test if voters condition their support for specific policies that challenge democratic norms and principles based on whether their own party is in power. We call this phenomenon democratic hypocrisy: the difference in support for democratic norms when one's own party is in or out of power 11 Our proposition derives from the association between Us vs Them political polarization and democratic erosion globally (Somer, McCoy, and Luke, 2021; Haggard and Kaufman, 2021). The logic of this type of pernicious polarization creates a zero-sum game mentality, dislike and distrust of the opposing party, and perceptions of an existential threat to the nation or way of life from the opposing party. Thus, the polarized citizen's interest is in keeping their own party in power and the opposing party out of power, even at the cost of anti-democratic behavior (McCoy, Rahman, and Somer, 2018). In the U.S., intense partisan polarization has generated growing perceptions among both parties' supporters that the opposing party's policies pose a threat to the nation, nearly tripling from $16 \%$ to about $45 \%$ of the population between 1994 and 2016 (Doherty, Kiley, and Jameson, 2016). Hence, we further argue that democratic hypocrisy is exacerbated by increased pernicious polarization manifested either as hyper-partisanship (Huddy, Mason, and Aarøe, 2015) or threat perceived from the opposing party.

\footnotetext{
${ }^{1}$ Our concept of democratic hypocrisy resembles the distinction made by Graham and Svolik $(2020)$ between principled democrats (those willing to punish democracy-eroding candidates equally) and instrumental democrats (those willing to punish only democracy-eroding positions by candidates from the opposing party). In a conjoint experiment to choose among political candidates, they find voters are nearly $50 \%$ more lenient toward their own party's candidates regarding violations of democratic norms.
} 
One issue with testing this account is that in any given point in time, the party in power is fixed. For instance, while some recent observational studies have found a higher proclivity of conservatives to support democratic norm-eroding policies (Drutman, Diamond, and Goldman, 2018), it is unclear if these views are driven by individual differences, such as ideology (Malka et al., 2020) or the political context at the time of the study, like the party in power or the nature of elite messages (Drutman, Diamond, and Goldman, 2018). Thus, using one-shot observational survey data where the political context is fixed, it is difficult to distinguish between these mechanisms ? $^{2}$ Recent experimental studies have attempted to tackle these problems by evaluating candidate choices based on policies, partisanship and positions violating democratic principles, with mixed results. Carey et al. (2020) found that most voters are willing to punish democratic violators (except for polarization over voting access), while Graham and Svolik (2020) found that very few people punish democratic norm-violators in polarized contexts. But, these studies do not assess whether the toleration of democratic norm-eroding behavior will be stronger when one's preferred party is governing.

Thus, to effectively test democratic hypocrisy, we introduce experimental and quasiexperimental approaches to test democratic attitudes under different contexts of copartisans in power or not. First, we fielded a large online survey experiment implemented in the U.S. in August 2020, to measure support for a series of hypothetical measures that federal or state officials could take that challenge existing democratic norms and practices, for instance, to allow presidents to disregard court decisions they deem biased or allow governors to ban protests. We asked respondents to consider these policies after reading a hypothetical scenario in which either their own party or the opposing party wins a trifecta - president and both houses of Congress, as well as the governorship of their state, in the 2020 elections. Comparing support for norm violations across counterfactual scenarios when one's favored party is in vs. out of power we find that citizens whose preferred party is in power were $7 \%$ more likely to support anti-democratic policies and the strength of this effect depends on their partisan attachment. Finally, utilizing an experiment priming the threat posed by the opposing party, we find that citizens primed to think of ways the opposing party threatens them were twice as likely to engage in democratic hypocrisy.

\footnotetext{
${ }^{2}$ We note that, due to the general norm that democracy is good, broad direct questions about support for democracy may also be subject to social desirability bias and not a good indicator of democratic attitudes (Svolik, 2019).
} 
One limitation of our experiment is that we cannot force respondents to think about these democracy-eroding policy positions in the context of the hypothetical future election we describe. First, this design choice limits the ecological validity of our study as respondents may not respond to these questions as if they were actually in these scenarios. Second, because we do not observe whether subjects followed our prompt to think hypothetically, we cannot identify the role of non-compliance in our relatively modest treatment effects. Third, it is possible that the two scenarios (i.e. Democrats vs. Republicans winning the trifecta) differed in their plausibility and supporters of the two parties differed in their ability or motivation to respond to these questions in the context of the scenarios to which we assigned them; thus we are limited in our ability to assess partisan differences in democratic hypocrisy.

To address these issues and probe the validity of our results by using observational data, we compare support for norm erosion between Democrats and Republicans across states with different governors and across time under different administrations. These analyses confirm our main finding: the supporters of both parties were much more supportive of norm-erosion when their co-partisans were in power. These analyses also reveal that variation in support for norm eroding practices is likely to be driven by a combination of partisan differences as well as the party currently in power.

\section{Research design}

To understand the prevalence and motivations behind democratic hypocrisy we implemented a survey experiment ( $n=7,899$, after pre-registered exclusions $\left.{ }^{3}\right)$ in which we measured five democratic norm-eroding policy choices as the outcome while manipulating (1) the salience of threat from the respondents' opposing party and (2) the identity of the party in power. We complement our experimental data using 6 waves of surveys from the Latin American Public Opinion Project (LAPOP).

\section{Survey experiment}

Our experiment was embedded in a multi-investigator survey fielded in August 2020 through Luc.id, the largest US marketplace for online panels $4_{4}^{4}$ Lucid offers quotasampling on demographic variables including: age groups, gender, race and region. In

\footnotetext{
${ }^{3}$ Our study was included in a multi-investigator project including several other batteries. As increased funding became available from other investigators our sample sized ended up larger than expected.

${ }^{4}$ We obtained consent from participants by providing a brief description of the research project on the first screen of the survey and asking for their voluntary participation. We did not use deception of any kind. Respondents
} 
order to enhance data quality, we screened out inattentive respondents using a pretreatment attention check Berinsky, Margolis, and Sances (2014). On the one hand, this improves the power of our study; on the other hand it may compromise its external validity if inattentive subjects are systematically different from those who passed this screener. In general, even though there is evidence showing that treatment effect estimates obtained on Luc.id match those obtained on probability samples quite well (Coppock and McClellan, 2019), we are measured in our interpretation of our findings. Given that Luc.id is an opt-in online panel our results should be interpreted as Sample Average Treatment Effects and may not generalize to the general U.S. population. (Franco et al., 2017)

At the beginning of the survey, we measured party identity (PID) with the typical ANES questions. We forced independents to choose which party deals better with "issues most important to" them, allowing us to assign independents to the in- and out-party conditions for the stimuli. Besides PID, we also obtained pre-treatment measures of expressive partisanship (partisanship as a social identity) developed by Huddy, Mason, and Aarøe $(2015) \cdot 5$

We study citizens' support for five democratic norm-eroding policy choices ranging from challenging an existing norm within constitutional bounds (the legislative majority changing the size of the Supreme Court over the objection of the opposition) to legally ambiguous (prosecute a journalist who accused the governor of misconduct) to more egregiously democracy-eroding actions curtailing checks and balances, civil liberties and minority rights (allowing government officials to disregard court decisions they think are politically biased, giving the governor power to ban protests, and giving the president the power to disqualify candidates he believes to be disloyal to the country. $6^{6}$

In the first arm of the experiment we introduced priming in which we randomly assigned a subset of the respondents to an elaboration task before they proceeded to answer our outcome measures. In particular, they were asked two questions we designed to prime

were paid $\$ 1$ (the standard compensation offered by Lucid) for a 15 minute survey. Lucid, or their vendors, compensated the participants.

${ }^{5}$ For independents, the party for which the expressive partisanship items were measured were based on the "forced choice" question. We opted for this strategy so that we can study democratic hypocrisy also for respondents with low levels of attachment, though we also report results separating out true independents in the Online Appendix.

${ }^{6}$ Question on disregarding courts was used by Carey et al. (2020), questions on banning protests and prosecuting journalists were used by Graham and Svolik (2020) and the remaining questions are original and designed with potential future comparative applications in mind. 
their feeling of out-group threat. First, we asked them to "list a few things that make you feel threatened about the Democrats/Republicans." Then, we asked them to think of things that make others who also support the respondent's preferred party feel threatened. In Online Appendix $\mathrm{C}$ we report descriptive analyses on the responses to this prime: it appears that the majority (56\%) identified a policy, while $14 \%$ reported a threat to democracy itself, $9 \%$ reported a threat from a specific politician, and $9 \%$ claimed not to feel threatened.7

The second arm of the experiment consisted of randomly assigning participants to either a condition in which their preferred party won the presidency, majority in Congress and the governorship of their state - which we call in-party condition, or a scenario where the participant's party lost and the opposing party is in power - which we call out-party condition 8 Thus, before responding to the policy choices, respondents were randomly assigned to two groups which received scenarios in which either the Democrats or the Republicans won control of most branches of government..$^{9}$ A third group of respondents were asked these items without describing a scenario of who is in power - in order to obtain a baseline measure of support for these policies.

\section{Observational data}

To complement our experimental approach we conducted two complementary analyses using observational data. First, using the responses in the condition in which no hypothetical scenarios were presented to the respondents, we used two of our survey questions to construct a measure of erosion that gauges support for giving governors power to ban protests or prosecute journalists accusing them of misconduct in the current political context. We compared this measure across Democrat vs. Republican respondents in states

\footnotetext{
${ }^{7}$ We also included a manipulation check asking participants about the extent they felt threatened by the possibility that the other party might win. We fail to find a statistically significant difference in this item across those that received the prime (a difference of 1 point on a 100 points scale with a standard error of 0.83 ). We suspect that this item may have elicited responses from those who don't feel threatened by the out-party as well as those who could not imagine the other party actually winning.

${ }^{8}$ Note that our vignettes do not discuss the margin of victory in the elections for either of these offices. Future studies should also investigate whether the margin of victory matters: do landslide scenarios make voters less concerned about needing to concentrate executive power, for instance? Or, as comparative examples suggest, even with super-majorities, do polarizing leaders continue to concentrate power and their supporters continue to vote for them.

${ }^{9}$ We believe both scenarios were believable at the time of our polling in mid-August 2020, with the exception of the House: fivethirtyeight.com forecast Biden's chances to win the presidency at $71 \%$, though Democrats were very conscious of similar predictions for Clinton before Trump's upset victory in 2016; Democrat's chances to win the Senate at $62 \%$; and House at $93 \%$.
} 
with Democrat vs. Republican governors to test the hypothesis that citizens are more supportive of erosion when the governor of their states is their co-partisan.

Second, we compiled repeated cross-section data from the Latin American Public Opinion Project (LAPOP) across four administrations from 2006-2019 on an item asking respondents if they thought that "when the country is facing very difficult times it is justifiable for the president of the country to close the Congress and govern without Congress?". We use this data to compare the partisan differences on this item across Republican and Democratic administrations. To our knowledge this is the first such effort to compare these responses across administrations to assess democratic hypocrisy.

\section{Results}

To estimate democratic hypocrisy, we compare our measure of support for democratic norm erosion across scenarios where co-partisans vs. the opposing party is in power, i.e. the in-party vs. out-party conditions. The left side of Figure 1A shows strong evidence of democratic hypocrisy: the difference we observe amounts to $2 \%$-points ( a $7 \%$ increase over the mean in the out-party condition, $\mathrm{p}$-value $=0.021)$. To put this difference in context, we note that our treatment effect is equivalent to about one fifth of the average difference between Democrats and Republicans who responded to these questions without reading about the hypothetical election (Figure OA3 in the online appendix) 10

The right hand side of Figure 1A contrasts these differences in the absence of the threat prime with democratic hypocrisy among respondents who received the threat prime. To the extent that threat-perceptions, indeed, amplify democratic hypocrisy we would expect the effect of the in-party vs. out-party treatment to be larger in the presence of the threat-prime. This is exactly what we find. On average, the threat-prime more than doubled the degree of democratic hypocrisy $(1.9 \%+2.3 \%=4.2 \%)$ (see online appendix Table OA2). In other words, among subjects primed to feel threatened by the opposing party, differential support for norm erosion when their own party is in power is amplified.

To complement our experimental finding based on our threat prime we also explored

\footnotetext{
${ }^{10}$ In analyses reported in Online Appendix $\mathrm{C}$ we decompose this effect by comparing respondents exposed to the in-party and out-party scenarios to those that answered the questions without reading about any hypothetical scenarios. We show that respondents in the in-party condition are more norm eroding than those in the condition without any scenario; and the opposite holds for the the out-party condition. However, we are underpowered to precisely compare these effects with each other and they are individually not statistically significant from zero. Moreover, these comparisons are less straightforward in the sense that they contrast responses to hypothetical and actual policy dilemmas.
} 
whether a pre-treatment measure of "expressive" partisan identity (Huddy, Mason, and Aarøe, 2015), as another proxy of pernicious polarization, explained variation in the treatment effects. In particular, we tested the prediction that individuals who strongly identify as partisans would condition their support for norm-erosion more on who is in power. Using a non-parametric procedure developed by Hainmueller, Mummolo, and Xu $(2019)$, we found that more partisan citizens exhibit higher degrees of democratic hypocrisy (see Figure 1b). Taken together with our threat treatment effect, this result provides evidence of a causal link between pernicious polarization and democratic hypocrisy.

Figure 1: Democratic hypocrisy
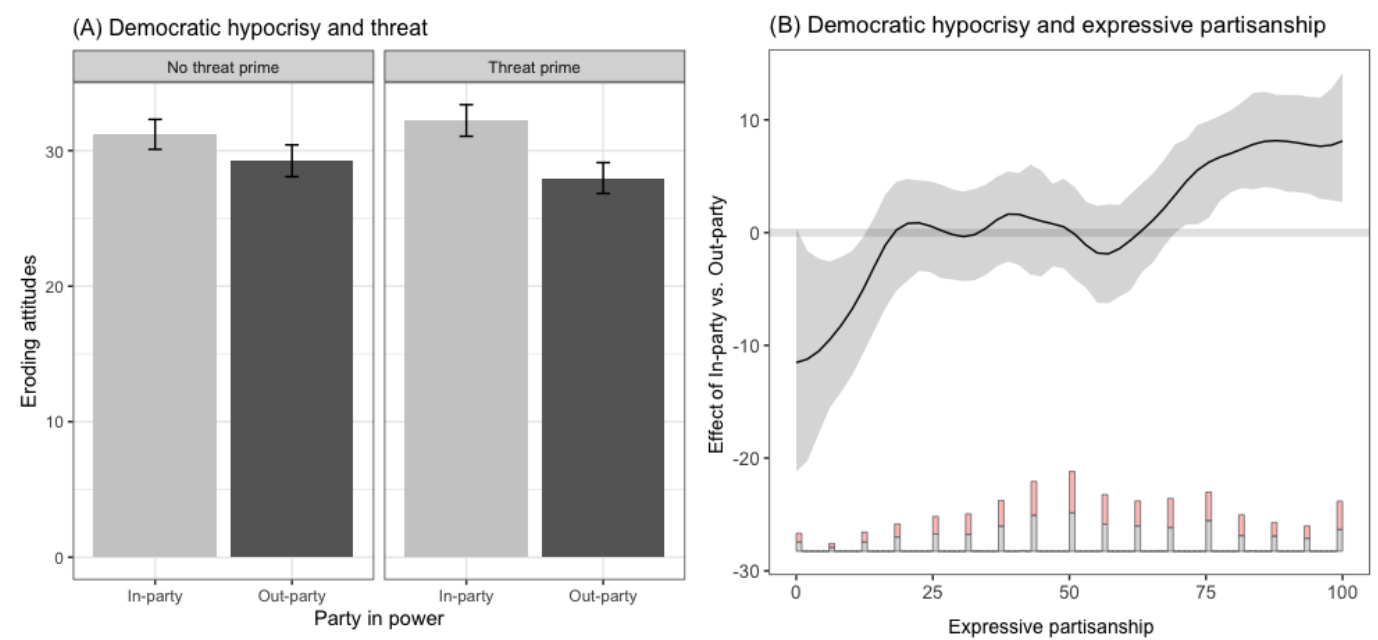

Note: (A): Bars are predicted means from a regression modeling the outcome as a function of experimental conditions, expressive partisanship and support for democracy (as declared in the PAP). Errors bars are 95\% confidence intervals based on robust standard errors. (B): Line depicts the marginal effect of in-party vs. out-party through the range of expressive partisanship estimated via interflex (Hainmueller, Mummolo, and Xu, 2019). The sample includes pure Independents; for them expressive partisanship was measured for the party they chose . Error bands are $95 \%$ confidence intervals based on bootstrap. Results are from the "No-threat prime" condition only.

We report our results from our observational studies in Figure 2. As shown in the left panel of the figure, both Democratic and Republican respondents were more supportive of policies granting anti-democratic powers to governors when the governor of their state was from their preferred party, though Republicans more so. Similarly, the right hand side of the figure reveals that Democrats and Republicans alike were much more likely to support giving a co-partisan president such rights. Both of these patterns are consistent with the notion of democratic hypocrisy.

Finally, we consider partisan differences in democratic hypocrisy across our studies. First, 
we find some tentative evidence (presented in Online Appendix C2) that Republicans exhibited a greater degree of democratic hypocrisy in our experiment. ${ }^{11}$ Second, our observational evidence suggests that Republicans were indeed more supportive of democratic erosion when a Republican president or governor was in power compared to Democrats when their co-partisan was in power. Thus, we expect that Republican support for democratic norm erosion may be a combination of individual characteristics and democratic hypocrisy, i.e. more norm-eroding when co-partisans are in power.

Figure 2: Observational evidence

(A) Support for erosion across states

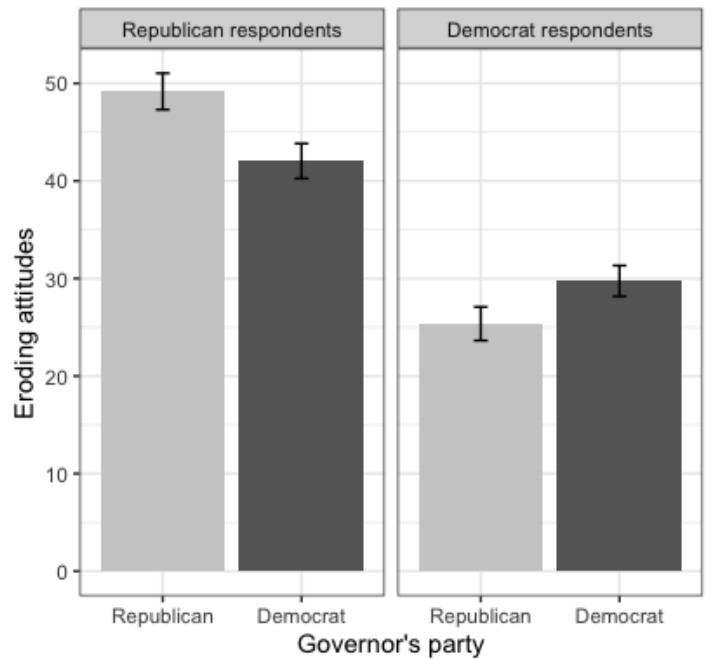

(B) Support for erosion across administrations

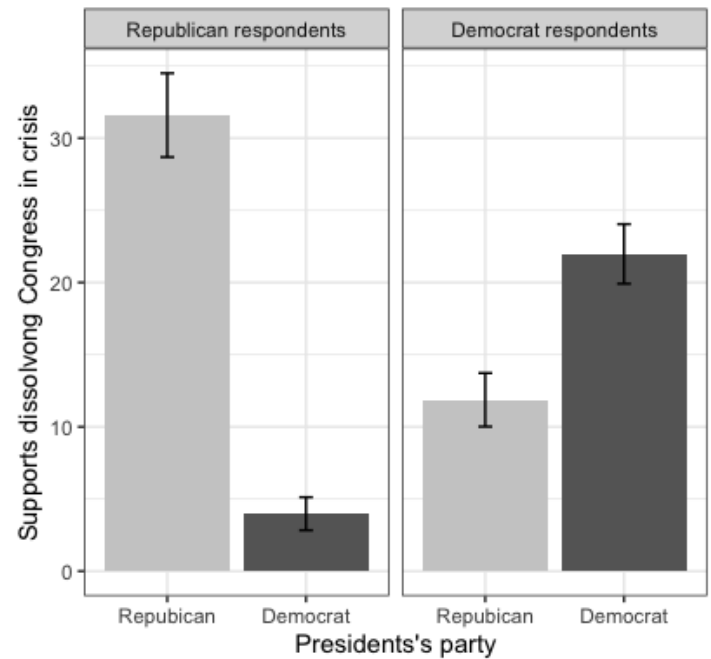

Note: (A): Bars are means of eroding attitudes based on a subset of questions pertaining to the powers of governors in the experimental condition without a hypothetical scenario presented. Errors bars are 95\% confidence intervals. (B): Bars are percent agreeing with the statement that "it is justifiable for the president to close the Congress in crisis". Data are from the each wave of LAPOP when it was included. Errors bars are 95\% confidence intervals.

\section{Conclusion}

There is mounting empirical evidence buttressing the concerns that American democratic resilience is fragile, vulnerable to stressors like Us vs. Them political polarization, and that public opinion cannot be counted on to be the bulwark to stop democratic erosion by leaders or parties intent on expanding their authority and entrenching their partisan advantage. Our study of democratic hypocrisy demonstrates that people's preferences on policies that erode democratic principles are heavily conditioned on partisan identities and preferences, and not abstract democratic ideals. Our experimental results further show that perceived threat of the opposing party and hyper-partisanship, indeed, have

\footnotetext{
${ }^{11}$ Not surprisingly, we also found that Independents exhibited the least amount of democratic hypocrisy.
} 
pernicious consequences for democracy by contributing to democratic hypocrisy. And our observational findings reinforce these patterns connecting partisan differences in support for norm-eroding policies to cross-sectional and temporal variation in the party of the national or state executive.

There remains the possibility that democratic hypocrisy may exist even in non-polarized contexts. Our observational data was collected in a polarizing context in the U.S. beginning in 2006, and our experiment was conducted in a severely polarized context. Thus, future studies should investigate whether democratic hypocrisy exists in non-polarized countries. Finally, future studies should also explore potential antidotes to polarization's pernicious consequences for democracy. For example, whether efforts to reduce perceptions of threat - such as reassurance of protection of rights and institutional changes to reduce the high stakes of winner-take-all elections - will reduce democratic hypocrisy and citizen support for democratic erosion.

\section{References}

Berinsky, Adam J, Michele F Margolis, and Michael W Sances. 2014. "Separating the shirkers from the workers? Making sure respondents pay attention on self-administered surveys." American Journal of Political Science 58 (3): 739-753.

Bermeo, Nancy. 2016. "On democratic backsliding." Journal of Democracy 27 (1): 5-19.

Carey, John, Katherine Clayton, Gretchen Helmke, Brendan Nyhan, Mitchell Sanders, and Susan Stokes. 2020. "Who will defend democracy? Evaluating tradeoffs in candidate support among partisan donors and voters." Journal of Elections, Public Opinion and Parties 1-16.

Coppock, Alexander, and Oliver A McClellan. 2019. "Validating the demographic, political, psychological, and experimental results obtained from a new source of online survey respondents." Research \& Politics 6 (1): 2053168018822174.

Diamond, Larry, Marc F Plattner, and Condoleezza Rice. 2015. Democracy in decline? Johns Hopkins University Press.

Doherty, Carroll, Jocelyn Kiley, and Bridget Jameson. 2016. "Partisanship and political animosity in 2016." Pew Research Center 75. 
Drutman, Lee, Larry Diamond, and Joe Goldman. 2018. "Follow the Leader: Exploring American Support for Democracy and Authoritarianism." Democracy Fund Voter Study Group .

Franco, Annie, Neil Malhotra, Gabor Simonovits, LJ Zigerell et al. 2017. "Developing standards for post-hoc weighting in population-based survey experiments." Journal of Experimental Political Science 4 (2): 161-172.

Graham, Matthew H, and Milan W Svolik. 2020. "Democracy in America? Partisanship, Polarization, and the Robustness of Support for Democracy in the United States." American Political Science Review 114 (2): 392-409.

Haggard, Stephan, and Robert Kaufman. 2021. Backsliding: Democratic Regress in the Contemporary World. Cambridge University Press.

Hainmueller, Jens, Jonathan Mummolo, and Yiqing Xu. 2019. "How much should we trust estimates from multiplicative interaction models? Simple tools to improve empirical practice." Political Analysis 27 (2): 163-192.

Huddy, Leonie, Lilliana Mason, and Lene Aarøe. 2015. "Expressive partisanship: Campaign involvement, political emotion, and partisan identity." American Political Science Review 109 (1): 1-17.

Malka, Ariel, Yphtach Lelkes, Bert N Bakker, and Eliyahu Spivack. 2020. "Who is Open to Authoritarian Governance within Western Democracies?" Perspectives on Politics $1-20$.

McCoy, Jennifer, Tahmina Rahman, and Murat Somer. 2018. "Polarization and the global crisis of democracy: Common patterns, dynamics, and pernicious consequences for democratic polities." American Behavioral Scientist 62 (1): 16-42.

Somer, Murat, Jennifer L McCoy, and Russell E Luke. 2021. "Pernicious polarization, autocratization and opposition strategies." Democratization 1-20.

Svolik, Milan W. 2019. "Polarization versus democracy." Journal of Democracy 30 (3): 20-32. 


\section{Online Appendix}

\section{A Questionnaire}

\section{A.1 Pre-treatment questions}

Party ID

Generally speaking, do you usually think of yourself as a Republican, a Democrat, an Independent, or what? [Republican, Democrat, Independent, Something else]

If party is selected: Would you call yourself a strong Republican or a not very strong Republican/Democrat? [Strong Republican/Democrat, Not very strong Republican/Democrat]

If party is not selected: Do you think of yourself as closer to the Republican or Democratic party? [Republican Party, Democratic Party, Neither]

If neither is selected: Think of the political issues most important to you. Do you feel Republicans or Democrats deal with these issues better? [Republicans, Democrats]

\section{Partisan Attachment}

How much do you have in common with other [Democrats/Republicans]? [Not At All, A Little, A Moderate Amount, A Lot, A Great Deal]

How well does the term [Democrat/Republican] describe you? [Not at all well, Not very well, Somewhat well, Very well, Extremely well]

How important is being a [Democrat/Republican] to you? [Not at all important, Not very important, Somewhat important, Very important, Extremely important]

When talking about [Democrats/Republicans], how often do you use "we" instead of "they"? [Never, Rarely, Some of the time, Most of the time, All of the time] [Only the in-party politician/party is displayed]

\section{A.2 Experiment Response Items.}

\section{INTRODUCTION}

For the next set of questions about the government, imagine this scenario: It's January 2021, and the new president, Congress and state level officials are being inaugurated 
following the 2020 elections. The [Democrats/Republicans] have made a sweep, winning the presidency, the Congress, and the governorship of your state.

- Change Supreme Court: It is 2021, and the [Democrats/Republicans] have captured both houses of Congress and the presidency. They have the opportunity to change the Supreme Court. The Constitution does not state how many justices should be on the Supreme Court and in the 19th century the Congress changed the number of justices several times. Some people say that the majority in the legislature should be able to change the number of justices on the Supreme Court, even if the opposing party disagrees. Others say that the Supreme Court should stay at the current size of nine justices, regardless of their current ideology. What do you think?

- Supreme Court size should stay the same

- The Senate should change the number of justices to swing its ideology

- Ban Protests: Imagine that the [Democrats/Republicans] have won the governorship in your state in the 2020 elections and must decide how to handle growing protests in your state. In this scenario, do you think that the governor should be allowed to ban protests, or is it more important to defend the right to protest, even by extremists

- Governor should NOT be allowed to ban protests

- Governor should be allowed to ban protests

- Prosecute journalists: The [Democrats/Republicans] have won the governorship in your state. The new governor is pushing the authorities to prosecute a journalist who accused the governor of misconduct. In this scenario, should the governor have the right to prosecute this journalist?

- Yes, governor should have the right to prosecute

- No, governor should not have the right to prosecute

- Disqualify candidates:It's 2021 and the [Democrats/Republicans] have won the presidential election. To protect the country, the president now wants to disqualify candidates who are disloyal to the country from running for office. In this scenario, 
should the president have the power to disqualify candidates the president believes to be disloyal to the country?

- President should have the right to disqualify candidates

- President should not have the right to disqualify candidates

- Disregard Biased Courts: Imagine that it's 2021 and the [Democrat/Republican] have won the presidency and the majority in Congress and the newly-elected [Democrats/Republicans] are questioning the impartiality of the courts. Some people say that elected officials must obey the courts even when they think that the decisions are politically biased against the president's party, while others argue that elected officials should not be bound by court decisions they regard as biased. What do you think?

- Court rulings should always be obeyed

- Some court rulings should be disregarded

\section{B Summary statistics and full regression results}

We use data on the following demographic variables:

- Age: Measured in years.

- Gender

- Race: Collapsed to a thricotomous indicator for White, Black and Hispanic with other responses coded as White

- Education: Recoded to four categories (no HS diploma; HS diploma; Some college; College degree; Post-grad degree)

- Partisan identification: Democrats, Republicans, Independents (with leaners included with their respective parties) 
Table OA1: Summary statistics and balance on demographics

\begin{tabular}{|c|c|c|c|c|c|c|}
\hline Scenario & All & \multicolumn{2}{|c|}{ In-party } & \multirow{2}{*}{$\begin{array}{l}\text { None } \\
\text { No }\end{array}$} & \multicolumn{2}{|c|}{ Out-Party } \\
\hline Threat-prime & & No & Yes & & No & Yes \\
\hline Age & 45.3 & 45.5 & 45.3 & 44.8 & 45.8 & 45.1 \\
\hline Female & $51.5 \%$ & $50.2 \%$ & $50.9 \%$ & $51.2 \%$ & $52.1 \%$ & $53.1 \%$ \\
\hline White & $72.7 \%$ & $73.5 \%$ & $71.6 \%$ & $71.6 \%$ & $73.4 \%$ & $73.3 \%$ \\
\hline College & $42.7 \%$ & $43.2 \%$ & $42.5 \%$ & $44.0 \%$ & $42.3 \%$ & $41.5 \%$ \\
\hline Republican & $41.0 \%$ & $40.8 \%$ & $41.3 \%$ & $40.4 \%$ & $41.3 \%$ & $41.3 \%$ \\
\hline Independent & $14.9 \%$ & $14.0 \%$ & $14.5 \%$ & $15.7 \%$ & $15.2 \%$ & $15.2 \%$ \\
\hline Democrat & $44.0 \%$ & $45.3 \%$ & $44.2 \%$ & $43.8 \%$ & $43.5 \%$ & $43.4 \%$ \\
\hline Expressive partisanship & 55.0 & 55.8 & 54.9 & 54.2 & 55.0 & 55.1 \\
\hline
\end{tabular}

Note: Entries are unweighted means. All variables are in percentages except Expressive partisanship (0-100 scale) and age (years.)

Table OA2: Regression estimates for Figure 2

\begin{tabular}{lccc}
\hline \hline \multicolumn{3}{c}{ DV: Support for erosion $(\%)$} \\
\hline In-party & $1.9^{*}$ & $4.3^{*}$ & $1.9^{*}$ \\
& {$[0.8]$} & {$[0.8]$} & {$[0.8]$} \\
Threat-prime & & & -1.3 \\
& & & {$[0.8]$} \\
In-party X Threat-prime & & & $2.3^{*}$ \\
& & & {$[1.2]$} \\
Expressive partisanship & $0.2^{*}$ & $0.2^{*}$ & $0.2^{*}$ \\
& {$[0.0]$} & {$[0.0]$} & {$[0.0]$} \\
Support for democracy & $6.2^{*}$ & $5.8^{*}$ & $6.0^{*}$ \\
& {$[0.4]$} & {$[0.4]$} & {$[0.3]$} \\
Constant & $7.6^{*}$ & $7.9^{*}$ & $8.4^{*}$ \\
& {$[1.4]$} & {$[1.3]$} & {$[1.1]$} \\
Observations & 3,185 & 3,145 & 6,330 \\
R-squared & 0.100 & 0.092 & 0.096 \\
\hline Threat-prime & No & Yes & All \\
\hline \hline
\end{tabular}

Note: Estimates from linear regressions. Robust standard errors in brackets. ${ }^{*}$ significant at $5 \%$. 


\section{Additional analysis}

\section{C.1 Analysis of responses to the threat prime}

As our manipulation check meant to assess the effectiveness of the threat prime was ambiguously worded and thus difficult to interpret the results, we used the responses to the elaboration task to assess if these essays indeed reflected perceived threat from the opposing party. Specifically, we coded $10 \%$ of the responses in this condition (a total of 293 respondents) according to their written response to the first prompt: Previously in the survey you indicated that you identify with the [Democrats/Republicans]. Many [Democrats/Republicans] say that they feel threatened by the policies and ideas that the [out-party]s advocate. Could you list a few things that make you feel threatened about the [out-party]s? We coded whether answers mentioned a specific policy such as health policy, abortion, voting, taxes; or whether they mentioned a threat to democracy itself such as voter suppression or socialism. We also found that some felt threatened by a specific politician so we coded that separately, as well as whether they said they did not feel threatened and thus did not have an answer. Finally, although we did not ask them how they feel, we did not if they expressed a fear emotion or a negative sentiment about the other party. Some respondents included more than one item in their responses and thus responses do not add up to 100. Table OA3 showed that over half mentioned a policy threat, whereas $14 \%$ were worried that democracy itself is threatened by the other party.

Table OA3: Content Analysis of Threat Prime

\begin{tabular}{ll}
\hline & (\% of respondents writing content (policies and ideas) and/or emotions) \\
\hline $56.3 \%$ & Content: Policy \\
$14.0 \%$ & Content: Democracy itself threatened \\
$8.9 \%$ & Content: Threatening Person \\
$6.1 \%$ & Fear Emotion: fear, distrust, afraid, anxious, threatened \\
$22.5 \%$ & Negative Sentiment: Dislike, hostility, insult, negative characteristics \\
$9.2 \%$ & Not threatened \\
$20.8 \%$ & Don't know, Refuse or Nonsense Answer \\
\hline
\end{tabular}

Note: We coded a random sample of respondents comprising $10 \%$ of subjects that received the threat-prime. Some respondents are included in more than one category in their responses and thus the categories do not sum up to $100 \%$.

We also searched for the most frequent phrases appearing in these tests to get a general sense of what Democrats and Republicans found threatening in the out-party. The frequent phrases indicate that Republicans are worried about socialism, taxes, gun control, 
abortion rights and police defunding under Democrats. Democrats are worried about Trump, rights, and people (perhaps referring to welfare and rights of people, including threats about healthcare, racism, gun violence).

Figure OA1: Frequently used words by Republicans in the essays on perceived threat

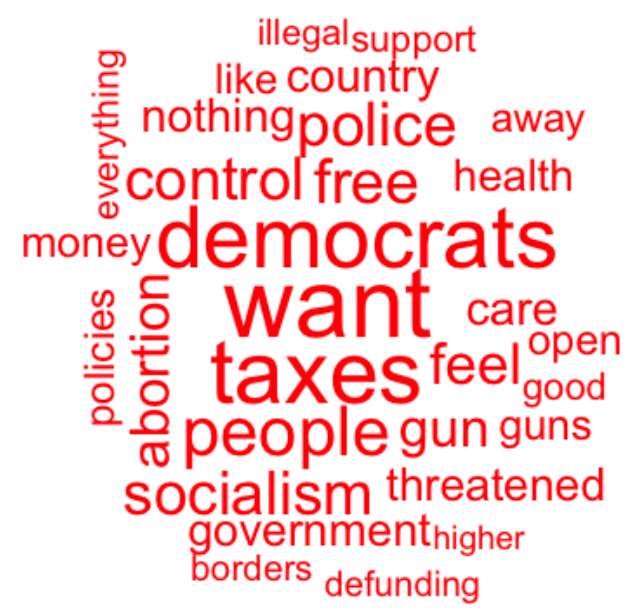

Figure OA2: Frequently used words by Democrats in the essays on perceived threat

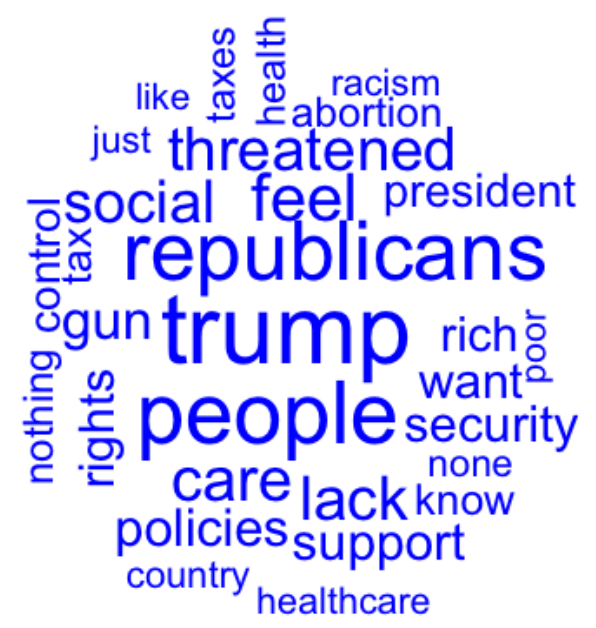

\section{C.2 Treatment effects by party}

As declared in our pre-analysis plan, we also estimated the magnitude of democratic hypocrisy (with and without exposure to the threat-prime) among partisan groups. Table 
OA4 reports our earlier estimates by party, first including Independents with the party they chose for the "forced-choice" question and then separating them as a third group.

Our estimates for partisan group are imprecise - not surprisingly, given that the treatment effects are quite small already on the full sample. We find some tentative evidence that Republicans exhibited more democratic hypocrisy in the absence of the threat-prime but the threat prime had a larger effect among Democrats. Not surprisingly, we find that Independents exhibit the least amount of hypocrisy - mirroring our finding on the role of expressive partisanship. While we report these results for the sake of transparency, we caution against reading too much into these differences given both the large uncertainty around our point estimates and the issue of differential non-compliance we discuss in the main text.

Table OA4: Experimental results by party

\begin{tabular}{|c|c|c|c|c|c|}
\hline \multirow[b]{3}{*}{ Party } & \multicolumn{5}{|c|}{ DV: Support for erosion (\%) } \\
\hline & \multicolumn{2}{|c|}{ Independents forced } & \multicolumn{3}{|c|}{ Independents not forced } \\
\hline & Republicans & Democrats & Republicans & Independents & Democrats \\
\hline \multirow[t]{2}{*}{ In-party } & $3.3^{* * *}$ & 0.9 & $4.3^{* * *}$ & -3.1 & 1.8 \\
\hline & {$[1.2]$} & {$[1.1]$} & {$[1.3]$} & {$[2.2]$} & {$[1.2]$} \\
\hline \multirow[t]{2}{*}{ Threat-prime } & -1.0 & -1.6 & -1.3 & -3.3 & -0.5 \\
\hline & {$[1.2]$} & {$[1.1]$} & {$[1.3]$} & {$[2.2]$} & {$[1.2]$} \\
\hline \multirow[t]{2}{*}{ In-party X Threat-prime } & 1.6 & $3.0^{*}$ & 2.1 & 3.9 & 1.8 \\
\hline & {$[1.7]$} & {$[1.6]$} & {$[1.8]$} & {$[3.0]$} & {$[1.7]$} \\
\hline \multirow[t]{2}{*}{ Expressive partisanship } & $0.2^{* * *}$ & $0.1^{* * *}$ & $0.3^{* * *}$ & $0.2^{* * *}$ & $0.1^{* * *}$ \\
\hline & {$[0.0]$} & {$[0.0]$} & {$[0.0]$} & {$[0.0]$} & {$[0.0]$} \\
\hline \multirow[t]{2}{*}{ Support for democracy } & $4.6^{* * *}$ & $7.1^{* * *}$ & $4.4^{* * *}$ & $5.6^{* * *}$ & $7.0^{* * *}$ \\
\hline & {$[0.3]$} & {$[0.4]$} & {$[0.4]$} & {$[0.6]$} & {$[0.5]$} \\
\hline \multirow[t]{2}{*}{ Constant } & $11.0^{* * *}$ & $7.9^{* * *}$ & $8.4^{* * *}$ & $14.3^{* * *}$ & $7.1^{* * *}$ \\
\hline & {$[1.4]$} & {$[1.6]$} & {$[1.6]$} & {$[2.5]$} & {$[1.8]$} \\
\hline Observations & 3,074 & 3,247 & 2,608 & 931 & 2,791 \\
\hline R-squared & 0.110 & 0.083 & 0.120 & 0.130 & 0.067 \\
\hline
\end{tabular}

Note: Estimates from linear regressions. Robust standard errors in brackets. ${ }^{*}$ significant at $5 \%$. 
Figure OA3: Norm violation by partisan groups

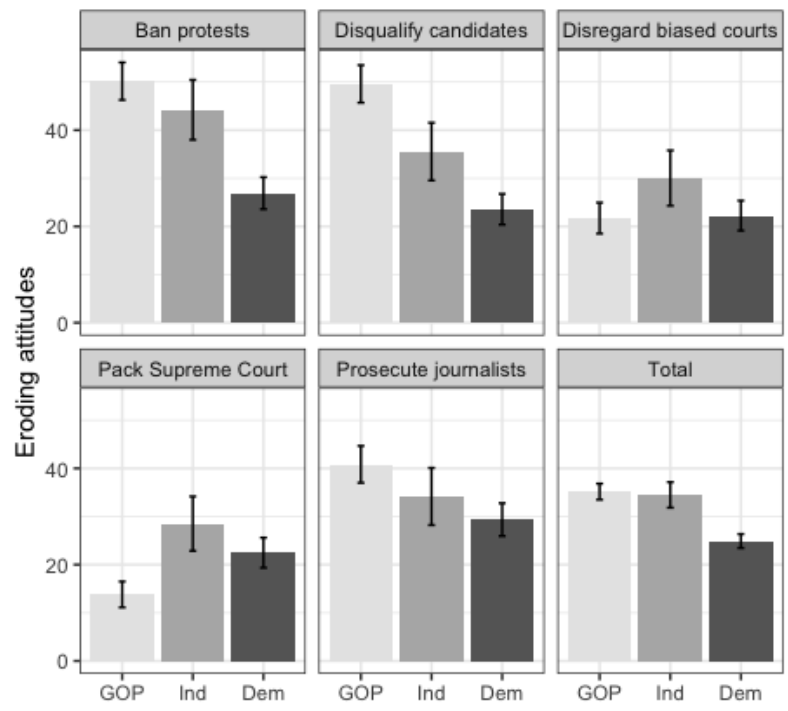

Note: Y-axis denotes (average) percent of people endorsing democracy eroding policies. Samples sizes are 686 for Democrats, 633 for Republicans and 246 for Independents.

\section{C.3 Results using the baseline condition}

Baseline support for our measures is shown in Figure OA3 based on a subset of 1,500 respondents who received the outcome questions without treatment. It is worrisome that a third to a half of Republicans and independents are ready to ban protests, disqualify candidates from running, and prosecute journalists. In the case of the latter, Democrats are not lagging much further behind. But we do not know if the increased support for democracy eroding policies is due to them being in power or some general Republican character. Support for packing or ignoring the courts is generally lower and more evenly distributed across the two parties. Puzzlingly, independents are the most ready to support these democratic erosions. Relatively smaller Republican support for these court related policies (both compared with their support for the other policies and, for the Supreme Court size, compared with the other groups) may be explained by the majority of federal judges, on both the lower and the Supreme Courts, being Republican appointed. Overall, Republicans (and surprisingly also independents) are more ready to support policies considered in line with democratic backsliding, but, once again, this could just be due to Republicans being in control of all three branches of government at the time of the data collection, with the exception of the House of Representatives.

Following the recommendation of one of our Reviewers we also report estimates comparing 
responses in the in-party and out-party condition to the baseline condition (i.e. the subset of respondents that responded to our outcome questions without reading either scenarios). Again, our estimates are too imprecise to parse out whether democratic hypocrisy is driven by winners increasing their support for anti-democratic policies, or rather losers reducing their demand for such measures.

Table OA5: Treatment effects compared to baseline condition

\begin{tabular}{lccc}
\hline \hline & \multicolumn{2}{c}{ DV: Support for erosion $(\%)$} \\
\hline In-party & 0.8 & 0.9 & 0.5 \\
Out-party & {$[0.8]$} & {$[1.2]$} & {$[1.1]$} \\
& -1.2 & $-2.4^{* *}$ & -0.5 \\
Expressive partisanship & $0.2^{* * *}$ & $0.2^{* * *}$ & $0.1^{* * *}$ \\
& {$[0.0]$} & {$[0.0]$} & {$[0.0]$} \\
Support for democracy & $5.9^{* * *}$ & $4.4^{* * *}$ & $7.1^{* * *}$ \\
& {$[0.3]$} & {$[0.4]$} & {$[0.5]$} \\
Constant & $10.0^{* * *}$ & $14.2^{* * *}$ & $7.9^{* * *}$ \\
\hline P(Inparty=outparty) & 0.017 & 0.005 & {$[1.7]$} \\
\hline Respondents & All & Republicans & Democrats \\
\hline Observations & 4,750 & 2,288 & 2,451 \\
\hline
\end{tabular}

Note: Estimates from linear regressions. Robust standard errors in brackets. ${ }^{*}$ significant at $5 \%$. Baseline is control condition. Excludes participants that were exposed to threat-prime 


\section{C.4 Observational results based on governor's party}

Table OA6: In-party governor and support for norm-erosion

\begin{tabular}{lccc}
\hline \hline & \multicolumn{3}{c}{ DV: Support for erosion $(\%)$} \\
\hline In-party governor & $7.1^{*}$ & $4.4^{*}$ & $5.7^{*}$ \\
& {$[3.0]$} & {$[2.1]$} & {$[1.9]$} \\
Expressive partisanship & $0.4^{*}$ & 0.1 & $0.2^{*}$ \\
& {$[0.1]$} & {$[0.1]$} & {$[0.0]$} \\
Support for democracy & 2.3 & $10.1^{*}$ & $5.0^{*}$ \\
& {$[1.3]$} & {$[2.0]$} & {$[1.0]$} \\
Republican respondent & & & $16.8^{*}$ \\
& & & {$[2.0]$} \\
Constant & $15.4^{*}$ & 2.4 & 3.7 \\
& {$[5.5]$} & {$[5.7]$} & {$[3.7]$} \\
\hline Respondents & Republicans & Democrats & All \\
Observations & 618 & 675 & 1,293 \\
R-squared & 0.064 & 0.056 & 0.091 \\
\hline \hline
\end{tabular}

Note: Estimates from linear regressions. Standard errors in brackets are clustered by state. * significant at $5 \%$. Includes only participants in the condition receiving no scenarios excluding pure independents. DV is constructed from items pertaining to the powers of Governors. 